\title{
Does intraperitoneal injection of propofol prior to detorsion improve testes weight and histopathological findings in a rat model?
}

This article was published in the following Dove Press journal:

Research and Reports in Urology

16 June 2017

Number of times this article has been viewed

\author{
Shahriar Amirhassani' \\ Sasan Mehrabi' \\ Seyed Mohammad \\ Hosseinipanah' \\ Abdolmajid Iloon \\ Kashkouli' \\ Saadat Torabian ${ }^{2}$ \\ Mohammad Kazem \\ Moslemi ${ }^{3}$ \\ 'Urology \& Nephrology Research \\ Center, Hamadan University of \\ Medical Sciences, Hamadan, Iran; \\ ${ }^{2}$ Health Policy Unit, Ministry of \\ Health and Medical Education, Tehran, \\ Iran; ${ }^{3}$ Department of Urology, Qom \\ University of Medical Sciences, \\ Qom, Iran
}

Correspondence: Sasan Mehrabi

Urology \& Nephrology Research Center, Beheshti Hospital, Eram Boulevard,

Hamadan 6516757666, Iran

Tel +988 II 8380704

Fax +988118380098

Email mehrabi.sasan@yahoo.com
Objectives: To determine the long-term preventive effects of intraperitoneal propofol on testicular ischemia-reperfusion injury in a rat model.

Materials and methods: Forty adult male albino Wistar rats were divided randomly into the following four groups according to the planned treatment ( $\mathrm{n}=10$ per group): group I, control; group II, sham-operated; group III, torsion/detorsion (T/D); and group IV, T/D plus propofol. Testicular ischemia was achieved by twisting the left testis $720^{\circ}$ clockwise (ie, applying torsion) for $1 \mathrm{~h}$. In the T/D plus propofol group (group IV), $50 \mathrm{mg} / \mathrm{kg}$ propofol was administered intraperitoneally 30 minutes before detorsion. Ipsilateral orchiectomy was performed under general anesthesia to determine the mean testicular weight and to enable histopathological examination of the testes using Johnsen's mean testicular biopsy score 30 days after the surgical procedure in all groups.

Results: The testicular weights in groups I, II, III, and IV were 1.65 $\pm 0.32,1.59 \pm 0.33,1.11 \pm 0.56$, and $1.08 \pm 0.50 \mathrm{~g}$ (mean $\pm \mathrm{SD})$, respectively. Testicular weight was significantly lower in the T/D groups (III and IV) than in both the control and sham-operated groups (I and II), but there was no improvement in testicular weight as a result of propofol administration. Similarly, Johnsen's mean testicular biopsy score was lower in groups III and IV than in groups I and II, but no positive effect was conferred by the administration of propofol in group IV.

Conclusion: The use of propofol in the treatment of testicular ischemia-reperfusion injury caused by testis torsion has no significant long-term therapeutic potential.

Keywords: testis, reperfusion, injury, propofol, rats

\section{Introduction}

Testicular torsion is a surgical emergency that mainly affects newborns, children, and adolescent boys. ${ }^{1,2}$ The prevalence of torsion in the USA is reportedly 8.6 per 100,000 males aged 10-19 years per year. ${ }^{3}$ The direct precipitating events are unknown, but may include undescended testis, cold temperature, and trauma or rapid growth at puberty, with some evidence for a familial predisposition. ${ }^{4}$ Previous studies have demonstrated a clear correlation between the duration of torsion and subsequent testicular function and suggest that at least partial testicular atrophy is not rare in patients who undergo detorsion as little as 4 hours after the onset of pain. ${ }^{5}$ Therefore, surgical detorsion should be performed as early as possible. ${ }^{1,6,7}$

While the mechanism underlying testicular tissue damage during torsion is not completely understood, current studies have demonstrated that the primary pathophysiological event is ischemia followed by reperfusion injury, ${ }^{1,8,9}$ which results in the production of abun- 
dant amounts of nitrogen and reactive oxygen species (ROS) in the reperfusion period due to substantial reoxygenation. ${ }^{1}$

In general, the ROS that are formed are eliminated by antioxidants, but where there has been excessive ROS production or failure of the cellular antioxidant defense system, exogenous antioxidants may confer potential benefit by neutralizing ROS. ${ }^{6}$ Several antioxidants or anti-inflammatory drugs such as allopurinol, caffeic acid phenyl ester, dehydroepiandrosterone, erdosteine, ibuprofen, morphine, $N$-acetylcysteine, propofol, resveratrol, and selenium have been investigated with a view to preventing ischemia-reperfusion injury in the testis. ${ }^{1,6,10,11,12}$ Propofol (2, 6-diisopropylphenol) is a widely applied anesthetic agent that exhibits potent antioxidant activity against lipid peroxidation both in vitro and in vivo, possibly due to its phenolic hydroxyl group, which acts like $\alpha$-tocopherol (vitamin E). ${ }^{13}$ The antioxidant activity of propofol has been demonstrated experimentally, both chemically and histologically, in the rat cerebrum, heart, intestinal mucosa, and joints. ${ }^{9-10,14-21}$

Several attempts have been made within the last few years to determine the effect of antioxidant agents on the outcome of spermatogenesis and fertility during torsion, but to the best of our knowledge little has been published about this subject, especially with regard to the long-term preventive effects of adjunctive antioxidant therapies such as propofol on spermatogenesis. Additional clinical data are thus needed.

The aim of the present experimental study was to determine whether propofol protects spermatogenesis from ischemia-reperfusion injury in rats.

\section{Materials and methods}

This prospective experimental study was approved by the Urology and Nephrology Research Center, Hamadan University of Medical Sciences, Hamadan, Iran, and by the Chancellor of Research and Technology of Hamadan University of Medical Sciences and was conducted at an animal laboratory between December 2013 and November 2014.

The study was designed so as to minimize the number of rats required for the examination. Therefore, 40 mature, male albino Wistar rats weighing 200-235 g and aged 70-90 days were selected randomly from the animal laboratory and housed under standard conditions in individual cages and in a temperature- and light-controlled room with free access to sterile animal food and water. For the 12 hours immediately preceding the study, they were given only water. The experiments were performed after receiving ethical approval from the Animal Care and Ethics Committee of Hamadan Univer- sity of Medical Sciences, in compliance with the principles of laboratory animal care (based on EU Directive 2010/63/ EU for animal experiments).

\section{Study protocol and groups}

The rats were randomly divided into the following four groups of 10 animals each according to the planned treatment, prior to which they were anesthetized with an intraperitoneal injection of $50 \mathrm{mg} / \mathrm{kg}$ ketamine hydrochloride $(50 \mathrm{mg} / \mathrm{mL}$ Ketamax, Rotexmedica, Trittau, Germany):

Group I (control group): required to determine the baseline values of histopathological parameters.

Group II (sham-operated): used to investigate the effect of surgical stress on spermatogenesis. The left testes were extracted through an ilioinguinal incision and then replaced by fixation to the scrotum without torsion.

Group III (torsion/detorsion [T/D]): the left testes were extracted through an ilioinguinal incision, and torsion was created by rotating them by $720^{\circ}$ in a clockwise direction, which was maintained by fixing them to the scrotum with a Prolene (Supa Medical Devices Company, Tehran, Iran) suture through the tunica albuginea, as described by Turner et $a .^{22}$ The suture was removed after 1 hour of torsion, and the left testis was untwisted and replaced into the scrotum for reperfusion (ie, detorsion). Orchiopexy was performed to prevent any new torsion during the assigned recovery period prior to final surgery.

Group IV (T/D plus propofol): the procedure was the same as for group III, but with the addition of an intraperitoneal injection of $50 \mathrm{mg} / \mathrm{kg}$ propofol (Propofol 1\% Fresenius, Fresenius Kabi, Uppsala, Sweden) 30 minutes before detorsion. The propofol dose and administration method were adopted from the study by Ünsal et al. ${ }^{23}$

In all groups, operations were performed under sterile conditions with the skin of the scrotal area shaved and prepared with $10 \%$ povidone-iodine solution before the operation. The scrotum was entered through a scrotal midline incision. The tunica vaginalis was opened, and the testes were delivered to the surgical field. After surgical intervention, the incision was closed using 4-0 silk sutures. After a brief recovery period from the anesthesia following the end of the experiment, the animals were allowed to consume food and water.

In all groups, ipsilateral orchiectomy was performed 30 days after the surgical procedure (or sham surgery) and reperfusion to determine mean testicular weights and enable histopathological examination of the testicular tissue using Johnsen's mean testicular biopsy score (MTBS). ${ }^{9}$ 


\section{Histological analysis}

All the rats were killed by cervical dislocation and the left testes was harvested 30 days after surgery (and reperfusion). All testes were weighed and evaluated with the aid of a light microscope (Nikon E200, Nikon Instruments Inc., Melville, NY, USA) by a pathologist who was blinded as to the treatment group from which they had been harvested. The testicular specimens were individually immersed in Bouin's fixative, dehydrated in alcohol, and then embedded in paraffin. The tissue blocks were sectioned at a thickness of 4-5 $\mu \mathrm{m}$, deparaffinized, and then stained with hematoxylin and eosin. ${ }^{24}$ Spermatogenesis was assessed histopathologically using Johnsen's MTBS. ${ }^{25}$ About 100 seminiferous tubules were evaluated for each testis, and a score of 1-10 was assigned to each tubule according to the degree of cell maturation under Johnsen's classification system, as follows: complete spermatogenesis, 10; germinal cell disorganization, 9; few spermatozoa, 8; no spermatozoa, 7; few spermatids, 6; no spermatids, 5; few spermatocytes, 4; spermatogonia only, 3; Sertoli cells only, 2; and no cells in the tubules, 1. Finally, the average MTBS was calculated for all tubules assessed in each testis. The groups were compared with each other according to testis weight and Johnsen's MTBS.

\section{Statistical analysis}

The data are reported as either mean \pm SD values (for quantitative variables) or percentages (for categorical variables). The groups were compared using the Mann-Whitney $U$ and Spearman correlations coefficient tests. Statistical software SPSS, version 14.0, for Windows (SPSS, Chicago, IL, USA) was used for all statistical analyses. The threshold for statistical significance was set at $p<0.05$.

\section{Results}

Forty male rats were evaluated in this prospective, randomized, experimental study, and all except three in group III (which were substituted) survived the follow-up period of 30 days after testicular T/D. The testicular weights in groups I, II, III, and IV were $1.65 \pm 0.32,1.59 \pm 0.33,1.11 \pm 0.56$, and $1.08 \pm 0.50 \mathrm{~g}$, respectively, and were significantly lower in the T/D groups (ie, III and IV) than in the non-T/D groups (I and II; $p=0.009$ ). The mean testicular weight did not differ significantly between groups III and IV $(p=0.912)$, indicating that there was no improvement in testicular weight with propofol administration, and it also did not differ significantly between groups I and II $(p=0.739)$. The testicular weights comparison between the four groups is shown in Table 1.
Similarly, the MTBSs were significantly lower in the T/D groups than in the control and sham-operated groups ( $p=0.000$ ), but no positive effect was conferred by the administration of propofol (ie, group III vs group IV, $p=0.315$ ). Comparison of Johnsen's MTBSs for the various groups is shown in Table 2. There was no significant correlation between mean testicular weight and Johnsen's MTBS $(p>0.050)$; on the other hand, in the presence of reducing Johnsen's MTBS, testicular weight was not necessarily reduced.

\section{Discussion}

Spermatic cord torsion is a urological emergency, and failure to diagnose the condition or late treatment may cause permanent testicular damage. ${ }^{26}$ Although the mechanism underlying testicular tissue damage during torsion is not completely understood, studies conducted thus far have demonstrated that the primary pathophysiological event is ischemia-reperfusion injury ${ }^{1,4,7}$ resulting in the production of abundant amounts of nitrogen and ROS in the reperfusion period due to a considerable oxygen supply. ${ }^{1}$ ROS are usually eliminated by antioxidants, but in the case of excessive ROS production or failure of the cellular antioxidant defense system, exogenous antioxidants are potentially beneficial for neutralizing ROS. ${ }^{6}$

Several antioxidants or anti-inflammatory drugs, including propofol, have been investigated with a view to preventing ischemia-reperfusion injury in the testis. ${ }^{1,6,10,11,12}$ Propofol has exhibited potent antioxidant activity against lipid peroxidation, as demonstrated in the rat, possibly due to its phenolic hydroxyl group, which acts like $\alpha$-tocopherol. ${ }^{13}$ As mentioned previously, evidence for this antioxidant activity in the rat

Table I Comparison of testicular weights in the experimental groups and the control group

\begin{tabular}{lll}
\hline Group & $\begin{array}{l}\text { Testicular } \\
\text { weight (g) }\end{array}$ & p-value \\
\hline Control & $1.65 \pm 0.32$ & - \\
Sham-operated & $1.59 \pm 0.33$ & 0.739 \\
Torsion/detorsion & $1.11 \pm 0.56$ & 0.023 \\
Torsion/detorsion plus propofol & $1.08 \pm 0.50$ & 0.009 \\
\hline
\end{tabular}

Notes: The data are given as mean \pm SD.

Table 2 Comparison of Johnsen's MTBSs between the experimental groups and the control group

\begin{tabular}{lll}
\hline Group & MTBS & p-value \\
\hline Control & $9.80 \pm 0.42$ & - \\
Sham-operated & $9.10 \pm 0.88$ & 0.052 \\
Torsion/detorsion & $5.10 \pm 2.56$ & $<0.001$ \\
Torsion/detorsion plus propofol & $6.20 \pm 1.81$ & $<0.001$ \\
\hline
\end{tabular}

Notes: The data are given as mean \pm SD.

Abbreviation: MTBS, mean testicular biopsy score. 
cerebrum, heart, intestinal mucosa and joints has already been published. ${ }^{9-10,14-21}$

Despite various attempts to determine the benefits of exogenous antioxidants with respect to the outcome of spermatogenesis following testicular torsion, there is a dearth of literature on the long-term preventive effects of adjunctive antioxidant therapies such as propofol on spermatogenesis. Therefore, additional clinical data are needed.

Taşkara et $\mathrm{al}^{27}$ investigated the long-term preventive effect of propofol on testicular ischemia-reperfusion injury in a rat model and found no apparent long-term therapeutic potential of this antioxidant in this context, despite the demonstrated short-term beneficial effects. Ünsal et $\mathrm{al}^{23}$ evaluated the attenuating effect of propofol on reperfusion injury after testicular T/D and concluded that the preference for propofol for anesthesia during the detorsion procedure may attenuate reperfusion injury. Finally, Yagmurdur et $\mathrm{al}^{28}$ performed two studies with an animal model of T/D to establish the mechanisms underlying the preventive effects of intravenous anesthetics and the preventive effects of propofol as an anesthetic agent on testicular ischemia-reperfusion injury. ${ }^{9}$ They concluded that as an anesthetic agent, propofol may attenuate germ-cell-specific apoptosis by decreasing nitric oxide biosynthesis and scavenging ROS and by inhibiting lipid peroxidation in this animal model.

Propofol was administered intraperitoneally as an antioxidant agent in male rats in the present prospective, randomized, experimental study in order to determine whether propofol protects spermatogenesis from ischemia-reperfusion injury. The data show that the ischemic injury produced by 1 hour of $720^{\circ}$ torsion of the spermatic cord resulted in significant atrophy and histological testicular failure, which are the known results usually observed with ischemia-related injury, suggesting the presence of irreversible injury to tissue viability over the long term. The reduction in testis weight and the observed histopathological testicular stress in the T/D groups suggest that torsion exerts a direct toxic effect on spermatogenesis and Johnsen's MTBSs. Nevertheless, propofol administration at the applied dose $(50 \mathrm{mg} / \mathrm{kg})$ and via the suggested route (intraperitoneal) cannot prevent ischemia-reperfusion-related injury to the testicular tissue; on the other hand, this method also did not result in significant rescue of testicular function by preserving the intact seminiferous tubular morphology in the testis.

\section{Study limitations}

This study was subject to some limitations that should be noted. The main limitation is that no biochemical measurements of chemical changes such as oxidative stress, oxidative damage, androgen levels, or immunological changes were made. In addition, the role of ketamine hydrochloride as a confounding factor may need to be evaluated in future studies. Finally, another different group (only propofol) for this study to evaluate the effect of propofol on testicular tissue and spermatogenesis was not considered.

\section{Recommendations}

The findings of the present study indicate that further investigations need to be performed, including assessments of the degree of vascular insufficiency, the use of pharmacological agents to evaluate the short- and longterm effects of oxidative stress, and the effects of torsion on long-term fertility.

\section{Conclusion}

The results of this study show that propofol has no significant long-term therapeutic benefits in the treatment of testicular ischemia-reperfusion injury caused by testis torsion. However, further evaluation of this issue is needed.

\section{Acknowledgments}

We thank the staff of the animal laboratory, the Urology and Nephrology Research Center, and the Chancellor of Research and Technology of Hamadan University of Medical Sciences, Hamadan, Iran, for their help during this study. We are also grateful to Shamsi Jaafari Baghenoei, Nasibeh Fathi, and Roghaye Noroozi for their collaboration during this investigation, including for help in interpreting the data. This study was approved and supported financially by the Chancellor of Research and Technology and by the Urology and Nephrology Research Center, Hamadan University of Medical Sciences, Hamadan, Iran. The funders played no role in the study design, data collection and analysis, decision to publish, or preparation of the manuscript.

\section{Disclosure}

All authors are employees of Hamadan University of Medical Sciences. The authors report no other conflicts of interest in this work.

\section{References}

1. Dokmeci D, Kanter M, Inan M, et al. Protective effects of ibuprofen on testicular torsion/detorsion-induced ischemia/reperfusion injury in rats. Arch Toxicol. 2007;81:655-663.

2. Cuckow PM, Frank JD. Torsion of the testis. BJU Int. 2000;86:349-353.

3. Mansbach JM, Forbes P, Peters C. Testicular torsion and risk factors for orchiectomy. Arch Pediatr Adolesc Med. 2005;159:1167-1171. 
4. Barthold JS. Abnormalities of the testis and scrotum and their surgical management. In: Wein AJ, Kavoussi LR, Novick AC, Partin AW, Peters CA, editors. Campbell-Walsh Urology, 10th ed. Philadelphia: Saunders Elsevier; 2012:3586-3593.

5. Sessions AE, Rabinowitz R, Halbert WC, Goldstein MM, Mevorach RA. Testicular torsion: direction, degree, duration and disinformation. J Urol. 2003;169:663-665.

6. Aksoy H, Yapanoglu T, Aksoy Y, Ozbey I, Turhan H, Gursan N. Dehydroepiandrosterone treatment attenuates reperfusion injury after testicular torsion and detorsion in rats. J Pediatr Surg. 2007;42:1740-1744.

7. Mäkelä E, Lahdes-Vasama T, Rajakorpi H, Wikström S. A 19-year review of paediatric patients with acute scrotum. Scand J Surg. 2007;96: 62-66.

8. Can C, Töre F, Tunçel N, et al. Protective effect of vasoactive intestinal peptide on testicular torsion-detorsion injury: association with heparincontaining mast cells. Urology. 2004;63:195-200.

9. Yagmurdur H, Ayyildiz A, Karaguzel E, et al. The preventive effects of thiopental and propofol on testicular ischemia-reperfusion injury. Acta Anaesthesiol Scand. 2006;50:1238-1243.

10. Cay A, Alver A, Küçük M, et al. The effects of N-acetylcysteine on antioxidant enzyme activities in experimental testicular torsion. $J$ Surg Res. 2006;131:199-203.

11. Koc A, Narci A, Duru M, Gergerlioglu HS, Akaydin Y, Sogut S. The protective role of erdosteine on testicular tissue after testicular torsion and detorsion. Mol Cell Biochem. 2005;280:193-199.

12. Salmasi AH, Beheshtian A, Payabvash S, et al. Effect of morphine on ischemia-reperfusion injury: experimental study in testicular torsion rat model. Urology. 2005;66:1338-1342.

13. Vasileiou I, Xanthos T, Koudouna E, et al. Propofol: a review of its non-anaesthetic effects. Eur J Pharmacol. 2009;605:1-8.

14. Moon C, Kim JS, Jang H, et al. Activation of Akt/protein kinase B and extracellular signal-regulated kinase in rats with acute experimental testicular torsion. J Vet Med Sci. 2008;70:337-341.

15. De La Cruz JP, Zanca A, Carmona JA, de la Cuesta FS. The effect of propofol on oxidative stress in platelets from surgical patients. Anesth Analg. 1999;89:1050-1055.

16. Ergün R, Akdemir G, Sen S, Taşçi A, Ergüngör F. Neuroprotective effects of propofol following global cerebral ischemia in rats. Neurosurg Rev. 2002;25:95-98.
17. Ozturk E, Demirbilek S, Kadir But A, et al. Antioxidant properties of propofol and erythropoietin after closed head injury in rats. Prog Neuropsychopharmacol Biol Psychiatry. 2005;29:922-927.

18. Kaptanoglu E, Sen S, Beskonakli E, et al. Antioxidant actions and early ultrastructural findings of thiopental and propofol in experimental spinal cord injury. J Neurosurg Anesthesiol. 2002;14:114-122.

19. Adembri C, Venturi L, Pellegrini-Giampietro DE. Neuroprotective effects of propofol in acute cerebral injury. CNS Drug Rev. 2007;13: 333-351.

20. Gülçin I, Alici HA, Cesur M. Determination of in vitro antioxidant and radical scavenging activities of propofol. Chem Pharm Bull (Tokyo). 2005;53:281-285.

21. Azeredo MA, Azeredo LA, Eleuthério EC, Schanaider A. Propofol and $\mathrm{N}$-acetylcysteine attenuate oxidative stress induced by intestinal ischemia/reperfusion in rats: protein carbonyl detection by immunoblotting. Acta Cir Bras. 2008;23:425-428.

22. Turner TT, Tung KS, Tomomasa H, Wilson LW. Acute testicular ischemia results in germ cell-specific apoptosis in the rat. Biol Reprod. 1997;57:1267-1274.

23. Ünsal A, Devrim E, Guven C, et al. Propofol attenuates reperfusion injury after testicular torsion and detorsion. World J Urol. 2004;22: 461-465.

24. Bancroft JD, Gamble M. Theory and Practice of Histopathological Techniques, 5th ed. Edinburgh: Churchill Livingstone; 2002: 76,130 .

25. Johnsen SG. Testicular biopsy score count-a method for registration of spermatogenesis in human testes: normal values and results in 335 hypogonadal males. Hormones. 1970;1:2-25.

26. Greenstein A, Schreiber L, Matzkin H. The effect of methylene blue on histological damage after spermatic cord torsion in a rat model. $B J U$ Int. 2001;88:90-92.

27. Taşkara E, Gör A, Kutlu O, et al. Does propofol prevent testicular ischemia-reperfusion injury due to torsion in the long term? Pediatr Surg Int. 2011;27:1003-1007.

28. Yagmurdur H, Ayyildiz A, Karaguzel E, Akgul T, Ustun H, Germiyanoglu C. Propofol reduces nitric oxide-induced apoptosis in testicular ischemia-reperfusion injury by downregulating the expression of inducible nitric oxide synthase. Acta Anaesthesiol Scand. 2008;52: $350-357$.
Research and Reports in Urology

\section{Publish your work in this journal}

Research and Reports in Urology is an international, peer-reviewed, open access journal publishing original research, reports, editorials, reviews and commentaries on all aspects of adult and pediatric urology in the clinic and laboratory including the following topics: Pathology, pathophysiology of urological disease; Investigation and treatment of

\section{Dovepress}

urological disease; Pharmacology of drugs used for the treatment of urological disease. The manuscript management system is completely online and includes a very quick and fair peer-review system, which is all easy to use. Visit http://www.dovepress.com/testimonials.php to read real quotes from published authors. 